$700 \mathrm{ft}$. above sea-level and in most directions give an effective range of transmission of about 40 miles. In his opinion, the best all-round wave-length for television is 7 metres, which does to a certain extent curve round hills to more distant points. A large number of tests have been carried out in all parts of London in receiving pictures from the Crystal Palace transmitter. Excellent pictures have also been received at some fifty sites ranging from Southend to Maidenhead and from Hatfield to Sevenoaks. In two years time, it may be possible to buy a complete set for the home for about 35 guineas. For cinema work, he thought that the best method is to use an intermediate film. A film is taken of the scene to be transmitted. It is then developed, fixed, washed and dried before being televised, the whole operation being less than two minutes. The first cinemas to receive their programmes by television would get them by radio transmission links. Later on, the big central radio transmitter might conveniently be replaced by a central distributing exchange point, which would receive the televising waves by cable from the outside point possibly twenty miles away.

\section{Italian Breakwater Construction}

On July 9, at the invitation of the Council, a special lecture, illustrated by lantern views, was delivered at the Institution of Civil Engineers, by Prof. E. Coen Cagli, of the School of Engineering of Rome. Prof. Cagli reviewed very exhaustively the progress made during recent years at Italian harbours and gave particulars of the present accommodation and equipment at the leading ports. He related how, on his recommendation, following an official visit a number of years ago to Great Britain for the purpose of studying British methods and practice, the vertical wall type of breakwater came to be adopted in Italy, and he stated that, with the exception of an unfortunate experience at Catania, attributable to absence of vertical bond in the structure, the results had been uniformly successful. He described the catastrophic storm of March 26-27, 1933, which caused the displacement of 700 lineal metres of newly constructed breakwater at that port and compared it with the similar catastrophe which befell the second arm of the Mustapha Jetty at Algiers on Feb. 2-3 of the following year (vide NATURE, 135, 143, Jan. 26, 1935), giving it as his opinion that these two incidents, on an analysis of the attendant conditions, only served to confirm his judgment in favour of the vertical wall breakwater. This type, moreover, had received further support from a series of experimental tests with small scale models, which he had been conducting with the co-operation of Prof. Stuckey at the hydrological laboratory of the University of Lausanne. Prof. Coen Cagli closed his lecture with a statement of the series of conclusions at which he had arrived on the basis of his experimental investigations.

\section{Foundation for Theoretical Biology at Leyden}

To promote the study and work in the field of theoretical biology, a foundation for theoretical animal and human biology has been established at the University of Leyden. In memory of Van der Hoeven (1801-68), professor of zoology in the University and author of the "Philosophia Zoologica", it is called "Prof. Dr. Jan van der Hoeven Stichting voor theoretische biologie van dier en mensch". The chief objects of the foundation are: (1) to arrange for lectures at the University of Leyden; (2) to bring Leyden biologists who are interested in theoretical biology into contact with their colleagues in Holland and abroad; and to promote the cooperation of theoretical biologists all over the world, for example, by arranging international symposia on theoretical biology; (3) to publish articles on theoretical biology; (4) to found a library on this subject. The directors of the Foundation are: Dr. C. J. van der Klaauw, professor of general zoology at the University of Leyden, Dr. J. A. J. Barge, professor of medical anatomy at the University of Leyden, and Dr. Adolf Meyer, professor of theoretical biology at the University of Hamburg.

\section{U.S. Stratosphere Balloon Explorer II}

MIsfortune has attended this latest attempt at stratosphere research. An account of the careful preparations that had been made jointly by the National Geographic Society and the U.S. Army Air Corps appeared in NATURE of June 22 (p. 1026) and the largest balloon ever designed was scheduled to be ready by June 1. A message in The Times of July 12 reports, however, that whilst the gondola was being attached on the previous day, the balloon burst for some unaccountable reason; the $375,000 \mathrm{cu}$. $\mathrm{ft}$. of helium were lost, and the five men working below had to jump for their lives to escape from the falling mass of the collapsing envelope. From the brief report it would appear as though the whole of the 8 tons upward force was too much for the initial cylindrical form assumed by the envelope, with the result that the top blew out.

\section{The New York Aquarium}

THE thirty-eighth annual report of the New York Zoological Society includes the report of the director of the Aquarium, Mr. Charles M. Breder, Jr., assistant director (June 1934). Some of the larger exhibits, including aquatic mammals, have been discontinued, but there is a larger number of fishes, so that the total number of species and specimens is greater than before. The work of the laboratory for the most part was concerned with studying various details of aquarium operation for the improvement of life conditions of fishes in captivity, including water chemistry, control of parasites and bacteria, food and breeding. A new antiseptic, 'mesthiolate', was found to be of distinct value in the control of secondary bacterial infection and in overcoming attacks of the protozoan Costia. Young brine shrimps, Artemia salina, reared from dried eggs supplied by the San Francisco Aquarium Society, have proved an excellent food for the sea-horses and other small fishes. With some little trouble, the shrimps may be raised to a considerable size suitable for larger species. 


\section{'Spot' Tests}

THE British Drug Houses, Ltd., London, N.1, has recently published a fourth edition of its book of reagents for 'spot' tests and delicate analysis $(2 s .6 d$., postage $4 d$.). The application of sixty-seven organic reagents is described, nearly twice the number given in the first edition which was issued three years ago. References are appended to each monograph. In addition to descriptive matter relating to 'spot' tests as applied to micro-analyses, the book includes adequate working details for many colorimetric determinations and larger scale methods of analysis in which organic reagents are employed. This firm also makes a 'spot' test outfit and issues a price list of the reagents mentioned in the book. The fact that the latter has reached a fourth edition in three years indicates that the use of these reagents is extending.

\section{Congress of Phonetic Sciences}

THE second International Congress of Phonetic Sciences will be held in London on July 22-26, when the following subjects among others will be discussed : the physiology of the voice, evolution of speech in the individual, its evolution in the history of mankind, influence of heredity, gesticulation, psychology of speech, the deaf-mute, problems of practical instruction in language, use of the gramophone, and speaking films. Further information can be obtained from Miss Parkinson, International Phonetic Congress, University College, W.C.1.

\section{International Congress on Population Problems}

AN International Congress for the Scientific Investigation of Population Problems will be held in Berlin on August 26-Sept. 1 next. Arrangements for the Congress are being made by the International Population Union in association with the German societies for the study of race, hygiene, statistics and public health. The president of the Congress is Dr. Eugen Fischer, director of the Kaiser Wilhelm Institute for Anthropology, Human Heredity and Eugenics, Berlin. The scientific proceedings of the Congress will be conducted in general and sectional meetings, the latter providing for communications dealing with population statistics, population biology and race hygiene, social, economic and psychological population problems, and medicine and hygiene. Specific topics of discussion are "The Problem of Births", "Town and Country", "Racial Hygiene", and "The Protection and Consecration of Life". The General Assembly of the International Union for the Scientific Investigation of Population Problems will be held on Monday, August 26, under the presidency of Sir Charles Close. The delegates will be received by the Government of the Reich, the city of Berlin, and the Oberburgermeister of Potsdam. Visits will be paid to scientific institutions, labour corps camps, etc., and arrangements have been made for an excursion to Saxon Switzerland. Particulars of the arrangements for the Congress may be obtained from the central office, Einemstrasse 11, Berlin, W.62.

\section{Beit Memorial Fellowships for Medical Research}

Ar the meeting of the trustees of the Beit Memorial Fellowships for Medical Research on July 12, it was announced that Prof. T. R. Elliott, professor of medicine in the University of London, and Prof. E. D. Adrian, Foulerton research professor of the Royal Society, have been appointed trustees in succession to the late Sir John Rose Bradford and to Sir Charles Sherrington respectively. Elections to fellowships were made as follows, the proposed subject and place of research being given in each case after the new fellow's name. Senior Fellowship (value $£ 700$ per annum) : Mr. R. Hill, to continue his studies on the respiratory function of hæmoglobin (Physiological Laboratory and the Molteno Institute, University of Cambridge). Fourth Year Fellowships (value $£ 500$ per annum): Dr. R. Gaddie, to continue his research on the metabolism of heart muscle (Departments of Medical Chemistry and Materia Medica, University of Edinburgh) ; Dr. J. M. Robson, to continue his work on the hormonic factors concerned in the maintenance of pregnancy and initiation of parturition (Institute of Animal Genetics, University of Edinburgh, or the School of Agriculture, University of Cambridge); Dr. F. G. Young, to study the diabetogenic factors of the anterior pituitary gland (Department of Physiology and Biochemistry, University College, London). Junior Fellowships (normal value $£ 400$ per annum): Dr. A. R. Todd, molecular structure of vitamin $\mathbf{B}_{\mathbf{1}}$ (Department of Medical Chemistry, University of Edinburgh); Mr. R. J. Kellar, the problem of nephritis and high blood pressure associated with pregnancy (London laboratories of the Royal College of Surgeons, and the Obstetric Unit, University College Hospital, London); Mr. N. L. Edson, fat metabolism and ketogenesis (Institute of Biochemistry, University of Cambridge); Dr. M. H. Salaman, investigation of the antigenic structure of the vaccinia virus (Lister Institute of Preventive Medicine, London); Dr. J. D. Fulton, experimental chemotherapy of malaria (London School of Hygiene and Tropical Medicine); Dr. Adèle H. Rosenheim, chemical nature of antibodies, especially those in antityphoid sera (Lister Institute of Preventive Medicine, London). The honorary secretary of the Beit Memorial Trustees is Prof. T. R. Elliott, University College Hospital Medical School, University Street, London, W.C.1.

\section{Leverhulme Research Fellowships and Grants}

Twenty nominations have been made to Leverhulme Research Fellowships tenable for varying periods up to two years. The new fellows and their subjects of research include the following: Dr. W. N. Bailey, senior lecturer in mathematics, University of Manchester, the study of functions of hypergeometric type; Prof. D. B. Blacklock, professor of tropical medicine, University of Liverpool, a study of the present practice of hygiene (including rural hygiene) in certain Eastern countries; Mrs. M. G. Blacklock, curator of the Museum, Liverpool School of Tropical Medicine, a comparative 